\title{
Arctic sea-ice variability is primarily driven by atmospheric temperature fluctuations
}

\author{
Dirk Olonscheck $\oplus^{1,2 \star}$, Thorsten Mauritsen $\oplus^{3}$ and Dirk Notz $\oplus^{1}$
}

\begin{abstract}
The anthropogenically forced decline of Arctic sea ice is superimposed on strong internal variability. Possible drivers for this variability include fluctuations in surface albedo, clouds and water vapour, surface winds and poleward atmospheric and oceanic energy transport, but their relative contributions have not been quantified. By isolating the impact of the individual drivers in an Earth system model, we here demonstrate that internal variability of sea ice is primarily caused directly by atmospheric temperature fluctuations. The other drivers together explain only $25 \%$ of sea-ice variability. The dominating impact of atmospheric temperature fluctuations on sea ice is consistent across observations, reanalyses and simulations from global climate models. Such atmospheric temperature fluctuations occur due to variations in moist-static energy transport or local ocean heat release to the atmosphere. The fact that atmospheric temperature fluctuations are the key driver for sea-ice variability limits prospects of interannual predictions of sea ice, and suggests that observed record lows in Arctic sea-ice area are a direct response to an unusually warm atmosphere.
\end{abstract}

$\Lambda$ lthough essential for understanding of the Arctic climate system, the quantitative relevance of the various possible mechanisms causing sea-ice variability is still unknown. Observations and reanalyses show that Arctic sea-ice area-tightly linked to atmospheric temperature fluctuations at the sea-ice interface-also significantly co-varies with Arctic mid-troposphere air temperature (Fig. 1, see Methods), suggesting that variability in sea-ice area might be mainly driven by fluctuations in atmospheric temperature ${ }^{1-4}$. However, the main driving mechanism of sea-ice variability remains unclear, because the observed link to atmospheric temperature fluctuations can be caused by both advected temperature fluctuations and local radiative feedbacks and forcings. Mechanisms that have been suggested to be relevant include the radiative feedbacks related to surface albedo ${ }^{4-6}$, clouds ${ }^{7}$ and water vapour $^{8,9}$, and the non-radiative forcings from surface winds ${ }^{10}$ and variations in poleward oceanic heat transport ${ }^{11-14}$. Because of strong coupling, disentangling the effects of these mechanisms is challenging using diagnostic methods.

Here we show that advected atmospheric temperature fluctuations are the primary driver of sea-ice variability. By systematically decoupling the other suggested drivers in a state-of-the-art Earth system model, we first demonstrate that local radiative feedbacks, the dynamical forcing by surface winds and variations in poleward oceanic heat transport are of minor relevance for sea-ice variability. In line with this finding, we then show that the key importance of atmospheric temperature fluctuations is robust across reanalyses and Coupled Model Intercomparison Project Phase 5 (CMIP5) simulations. We provide a complete quantification of the drivers of Arctic sea-ice variability throughout the entire seasonal cycle.

\section{Quantifying drivers of sea-ice variability}

To quantify the contributions of the suggested radiative feedbacks of surface albedo, clouds and water vapour, and non-radiative forcings by surface winds and poleward oceanic heat transport to seaice variability, we perform and analyse experiments with the Max Planck Institute Earth system model (MPI-ESM) 1.2-LR. In these experiments, we decouple the various suggested drivers-hereafter referred to as decoupled mechanisms-collectively and individually by prescribing them with randomly sampled fields from a preindustrial control simulation (see Methods). The randomization suppresses the autocorrelation on all atmospheric and oceanic ${ }^{15}$ timescales (from two-hourly to multidecadal). We compare the experiments in which one or all mechanisms are decoupled, and hence non-interactive, to the fully interactive control simulation (Fig. 2 and Supplementary Fig. 1). Atmospheric temperature fluctuations cannot be explicitly decoupled without also prescribing sea ice, but they are the remaining cause when all decoupled mechanisms are non-interactive. This allows us to separate out how much of Arctic sea-ice variability is driven by atmospheric temperature fluctuations alone and how much by the individual decoupled mechanisms. The sum of the annually averaged contributions from the individual decoupled mechanisms is similar to their joint impact, but synergies and interactions among these mechanisms can be strong ${ }^{16}$, causing slightly different results from an individual decoupled mechanism compared with the experiment in which all mechanisms are decoupled (Fig. 2b and Supplementary Fig. 1). In total, we find that the decoupled mechanisms acting together explain only $25 \%$ of the Arctic sea-ice variability, with the seasonally averaged contributions being larger in winter and spring than in summer and autumn (Supplementary Table 2). Regionally, the decoupled mechanisms primarily impact sea-ice variability in regions close to the edge of the sea ice, where the sea-ice concentration varies most in the control simulation (Fig. 3 and Supplementary Fig. 2). In March, the interactive mechanisms lead to an increase in the sea-ice variability mainly in the marginal ice zone south of the sea-ice edge at $15 \%$ ice concentration, and a decrease further north in the Bering Sea, whereas the Barents Sea shows the opposite pattern (Fig. 3a). These changes are mainly caused by the radiative feedbacks of clouds and water vapour ${ }^{17}$, with similarly small contributions from surface albedo, surface winds and oceanic heat transport in the Atlantic sector (Supplementary Fig. 3). In September, the combined interactive mechanisms increase the sea-ice variability (Fig. 3b).

${ }^{1}$ Max Planck Institute for Meteorology, Hamburg, Germany. ${ }^{2}$ International Max Planck Research School on Earth System Modelling, Hamburg, Germany. ${ }^{3}$ Department of Meteorology, Stockholm University, Stockholm, Sweden. *e-mail: dirk.olonscheck@mpimet.mpg.de 


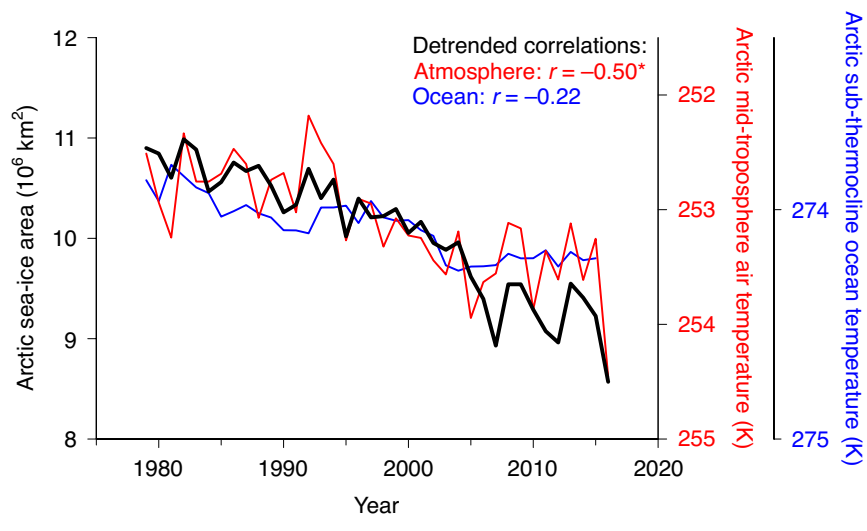

Fig. 1 | Evolution of Arctic sea-ice area, mid-troposphere air temperature and sub-thermocline ocean temperature from 1979 to 2016 . The annually averaged NSIDC passive microwave sea-ice concentration ${ }^{29}$, the ERA-

Interim reanalysis ${ }^{30}$ and the ORAS4 reanalysis ${ }^{31}$ are detrended to derive the indicated regression coefficients (see Methods). Correlations significant at 99.9\% are marked with an asterisk. The mid-troposphere air temperatures and sub-thermocline ocean temperatures are averaged across $60-90^{\circ} \mathrm{N}$. The detrended significant correlation of Arctic sea-ice area to $60-90^{\circ} \mathrm{N}$ $2 \mathrm{~m}$ air temperature is $r=-0.69$ (not shown). The $y$ axes are colour-coded to match the curves, note that the temperature $y$ axes are reversed and differently scaled for illustrative purposes.

This is primarily caused by the surface-albedo feedback, because in September all of the sea-ice cover receives shortwave radiation. The radiative effects from clouds partly oppose the impact of the surface-albedo feedback (Supplementary Fig. 3). The overall minor role of the decoupled mechanisms suggests that three-quarters of Arctic sea-ice variability is directly caused by atmospheric temperature fluctuations.

To test whether the role of the decoupled mechanisms might change in a warming world compared with pre-industrial conditions, we analyse the 100 ensemble simulations of the MPI Grand Ensemble (MPI-GE) (Maher, N. et al., manuscript in preparation) across the ensemble dimension for both the historical period and the IPCC representative concentration pathway (RCP) 8.5 emission scenario (see Methods). We find small changes in the variability of the driving variables that only become substantial when the Arctic sea-ice cover disappears (Supplementary Fig. 5). We conclude that the small increase in the variability of Arctic surface albedo, cloud cover, water vapour and poleward atmospheric energy transportand the small decrease in the variability of the Arctic surface winds and the poleward oceanic heat transport with the loss of the Arctic sea-ice cover-suggests no substantial change in the relative importance of the driving mechanisms of sea-ice variability, thus pointing towards the dominant role of atmospheric temperature fluctuations also under anthropogenic forcing. As a second line of evidence for the dominant role of atmospheric temperature fluctuations, we next specifically investigate the link between sea-ice variability and atmospheric and oceanic temperature fluctuations in MPI-ESM1.2-LR, the CMIP5 models, reanalyses and observations.

\section{Atmospheric and oceanic temperature fluctuations}

We determine the correlations between model-simulated $60-90^{\circ} \mathrm{N}$ atmospheric and oceanic temperature fluctuations and Arctic seaice variability (Fig. 4). At the surface, the annual mean atmospheric temperature shows a negative correlation with annual mean sea-ice area, because sea ice and atmospheric temperatures are tightly coupled within the Arctic boundary layer. The correlation weakens with height in all experiments (Fig. 4a, black and coloured solid lines).
Here we only analyse the tropospheric temperature variability above the Arctic boundary layer height ${ }^{18}$ to avoid a direct influence of sea ice on atmospheric temperature. The tropospheric mean temperature between 850 and $400 \mathrm{hPa}$ significantly correlates with sea-ice area at $r=-0.49$ in the interactive control simulation. By examining the spatial distribution of the correlation, we find that the negative correlation is largest at the sea-ice edge and is weakened by positive correlations in the Central Arctic (Fig. 4b). Collectively, the interactive mechanisms strengthen the dominant direct link between mid-tropospheric temperature fluctuations and sea-ice variability by about one-third compared with the experiment in which all mechanisms are decoupled $(r=-0.34)$. The poleward oceanic heat transport strongly contributes to this strengthening, suggesting that oceanic heat released to the atmosphere sustains the strong link between sea-ice variability and atmospheric temperature fluctuations, especially in the lower troposphere.

The oceanic temperature near the surface shows a significant negative correlation with annual mean sea-ice area. This correlation is unsurprising because sea ice and ocean temperatures are tightly coupled above the thermocline. Below the thermocline, however, the oceanic temperature non-significantly and weakly correlates with sea-ice area in the control simulation. Regionally, significant negative correlations occur only near the winter sea-ice edge in the Atlantic sector ${ }^{11}$ (Fig. 4c). Although an individual non-interactive radiative feedback or forcing can strengthen the negative correlation below the thermocline, the joint impact of the decoupled mechanisms on the correlation between sub-thermocline ocean temperature and sea-ice area is small (Fig. 4a).

To test how representative the results from MPI-ESM1.2-LR are, we determine the correlations between the Arctic atmospheric and oceanic temperature and Arctic sea-ice area from the pre-industrial control simulations for 41 CMIP5 models (Fig. 4a, grey lines; Supplementary Table 3 ). We find that the CMIP5 models consistently show negative correlations between mid-tropospheric temperature and sea-ice area that range from $r=-0.67$ to $r=-0.29$, and that MPI-ESM1.2-LR represents the mean CMIP5 correlation strength $(r=-0.48)$. We also find that the correlation between sub-thermocline ocean temperature and sea-ice area differs between the CMIP5 models $(r=-0.75$ to $r=0.09)$. Although a few models show a strong negative correlation that is nearly independent of depth, most models agree with the expected weakening of the correlation strength with depth, similar to the behaviour of MPI-ESM1.2-LR. We also find that MPI-ESM1.2-LR matches the correlations between observations of sea-ice area and reanalyses of temperature-especially in the lower and mid-troposphere and the upper $400 \mathrm{~m}$ of ocean depth (Fig. 4a, dotted line). In line with the minor role of the decoupled mechanisms, the similarity of the correlations in model-simulated pre-industrial conditions and the observational period suggests that the link between sea-ice variability and atmospheric temperature fluctuations is largely independent from anthropogenic forcing. Regionally, the observed correlation pattern between sea-ice variability and mid-tropospheric temperature resembles the simulated pattern, with negative correlations near the sea-ice edge and positive correlations in the Central Arctic (Supplementary Fig. 6a and Fig. 4b). The correlation pattern between sea-ice variability and sub-thermocline ocean temperature shows stronger negative correlations, especially along the sea-ice edge, compared to the simulated correlation strength (Supplementary Fig. 6b and Fig. 4c). Although the time series for observed sea-ice area and temperature reanalyses are short and show less-significant correlations, the patterns agree with the simulated correlation patterns. The representativity of both the mean Arctic correlation strengths and the correlation patterns modelled by MPI-ESM1.2-LR to the reanalyses gives us confidence that the radiative feedbacks and forcings acting collectively in the real world strengthen and weaken the negative correlations to atmospheric and oceanic temperatures analogously. 


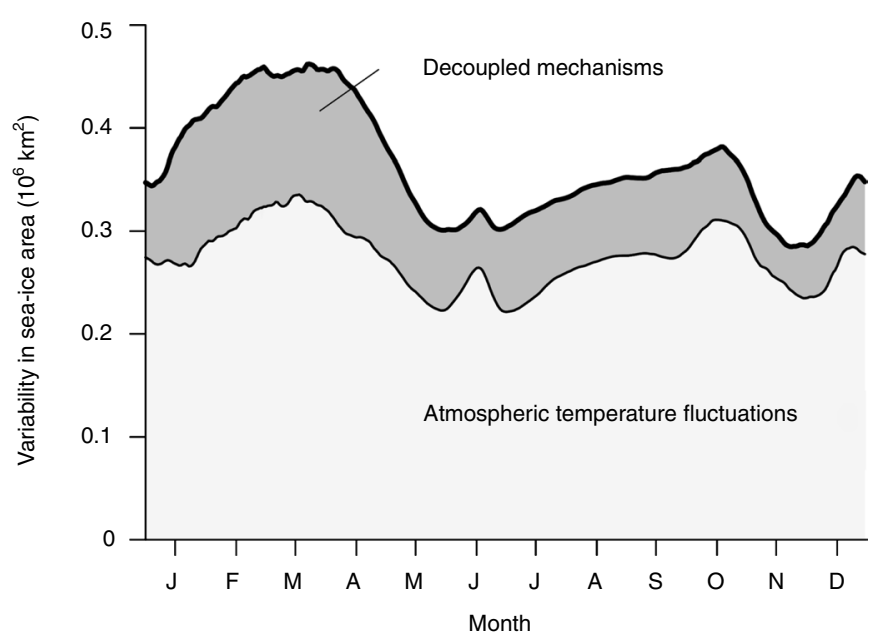

Average annual impact of individual mechanisms (\%)

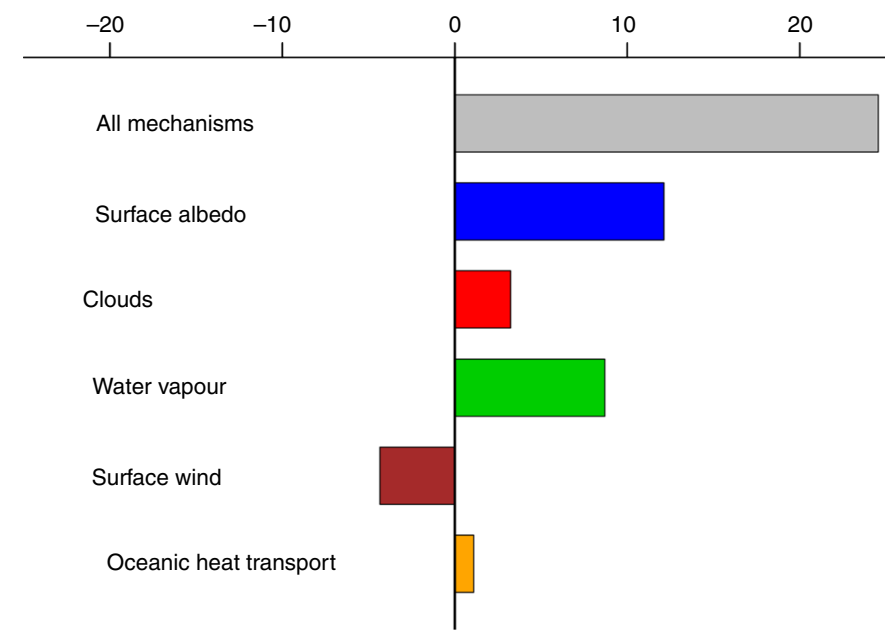

Fig. 2 Impact of decoupled mechanisms on the variability of the Arctic sea-ice area. a, Evolution of the multiyear daily standard deviation of Arctic seaice area with interactive mechanisms (control simulation, thick black curve) and without interactive mechanisms (the experiment with all mechanisms decoupled, thin black curve) throughout the year. The joint impact of the decoupled mechanisms on the variablity of the Arctic sea-ice area is shaded in dark grey and the impact from atmospheric temperature fluctuations is shaded in light grey. $\mathbf{b}$, Change in the multiyear daily standard deviation of the Arctic sea-ice area in the control simulation relative to the six experiments. The joint impact of the individual mechanisms is shown in grey.

a

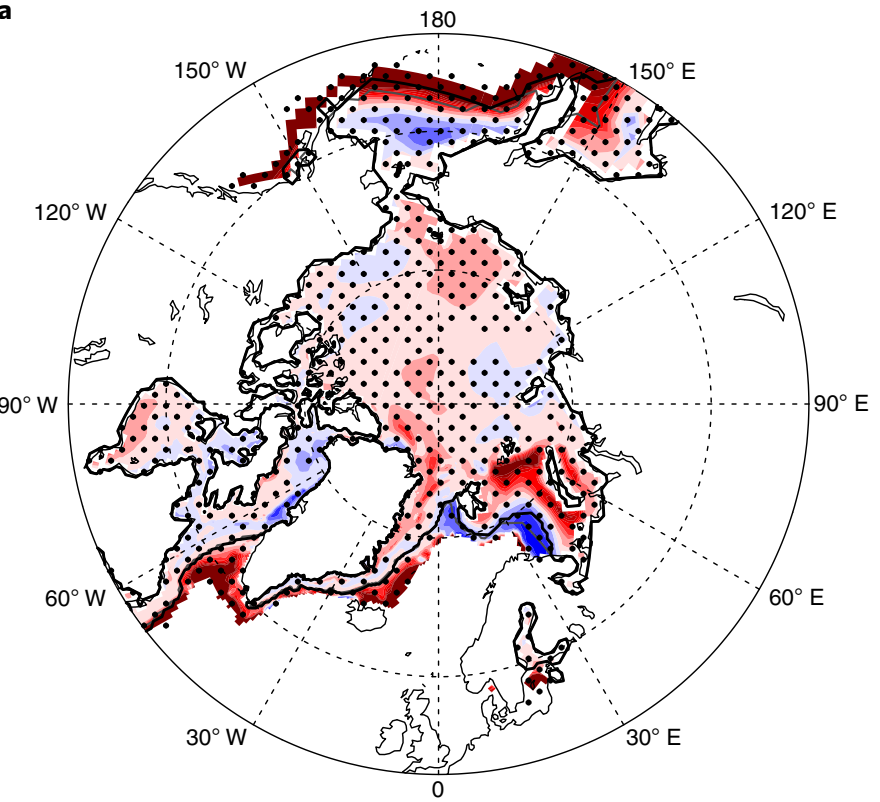

b

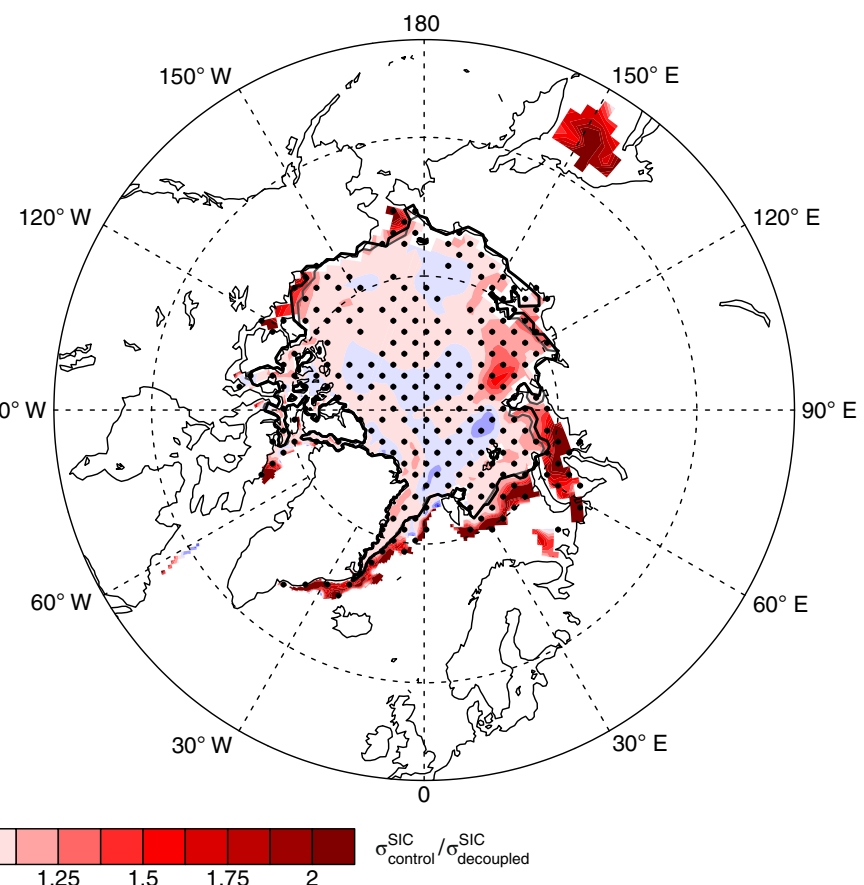

Fig. 3 Regional impact of decoupled mechanisms on Arctic sea-ice variability. a,b, Variability ratio of the sea-ice concentration (SIC) between the control simulation and the experiment with all mechanisms decoupled ( $\sigma_{\text {control }}^{\text {SI }} / \sigma_{\text {decoupled }}^{\text {SIC }}$ stippling represents $99.9 \%$ significance) in March (a) and September (b). Increased variability in SIC caused by the interactive mechanisms is shaded in red, whereas decreased variability is shown in blue. Changes in variability smaller than $1 \%$ are not shown. The sea-ice edge at $15 \%$ ice concentration, displayed as black and grey lines, is similar for both experiments. Note that absolute changes along the ice edge are small (see Supplementary Fig. 4).

\section{Origin of tropospheric temperature fluctuations}

When MPI-ESM1.2-LR is run with all mechanisms decoupled, the tropospheric temperature fluctuations driving sea-ice variability can only be caused by advection of atmospheric moist-static energy ${ }^{19,20}$, and local variations in ocean heat release to the atmosphere ${ }^{11}$ (compare Fig. 4a and Supplementary Fig. 9). To confirm the dominant role of advection for tropospheric temperature fluctuations, we determine the correlations between the surface pressure and midtropospheric temperature in the control simulation (Supplementary Fig. 7). We find a pattern similar to the positive phase of the North Atlantic Oscillation, but shifted to the northeast. In the NorwegianGreenland Sea a warm mid-troposphere is associated with a low 

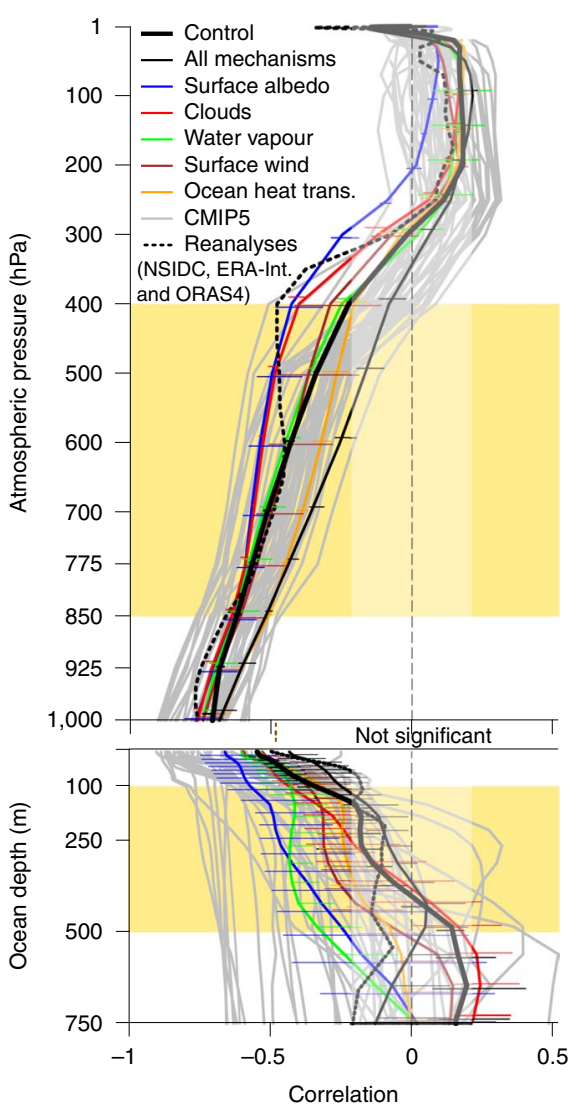

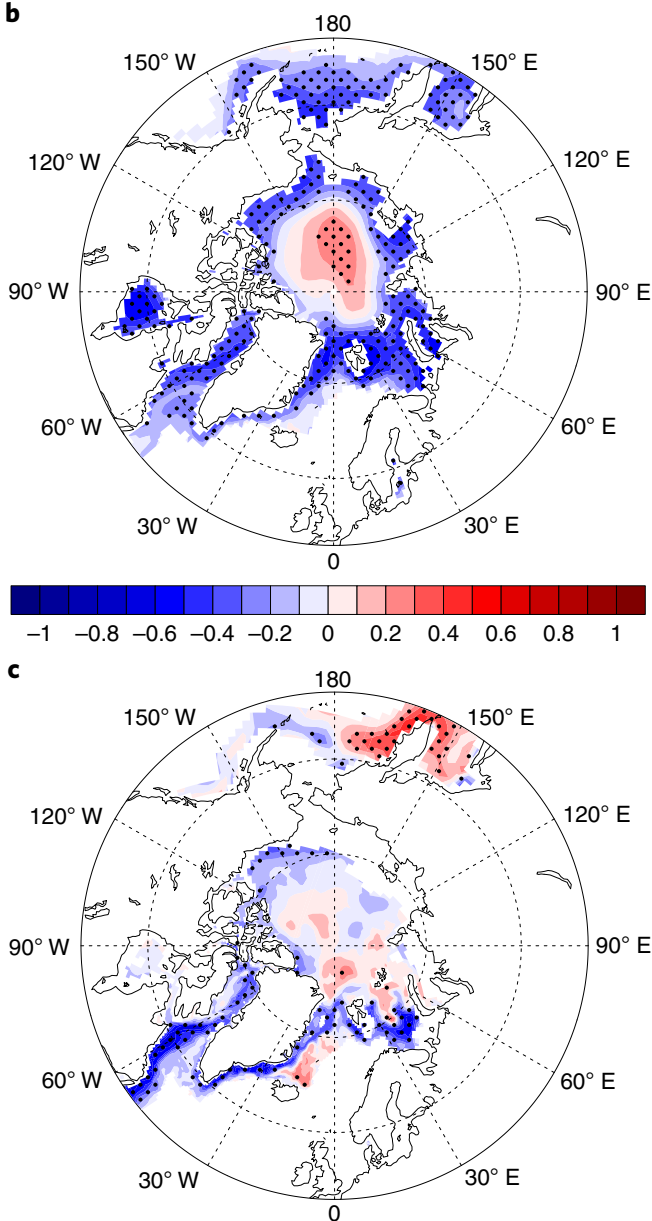

Fig. 4 | Linking sea-ice variability with atmospheric and oceanic temperature fluctuations. a, Correlation between annual Arctic sea-ice area and annual Arctic $\left(60-90^{\circ} \mathrm{N}\right)$ atmospheric and oceanic temperature in MPI-ESM1.2-LR without (thick black line) and with (thin lines) decoupled mechanisms, in 41 CMIP5 models (grey lines) and reanalyses (dashed line). Experiments are named by the individual non-interactive mechanism. Correlations are significant at $99.9 \%$ outside the marked vertical bar for all model simulations, and left of the brown dotted line (see top $x$ axis) for the reanalyses. The uncertainty derived from two 100-yr-long chunks (coloured horizontal lines) is staggered in each level for illustrative purposes. b,c, Correlation between the interannual variability of sea-ice concentration and atmospheric (b) and oceanic (c) temperature for the control simulation averaged across the midtroposphere and the sub-thermocline ocean depth, respectively (yellow boxes in a). Correlations significant at $99.9 \%$ are stippled.

surface pressure. The anticorrelation indicates baroclinic instability, which suggests that Arctic mid-tropospheric temperature is strongly influenced by poleward moist-static energy transport in the Atlantic sector storm tracks ${ }^{13,21}$. This poleward transport of extratropical air masses is mainly accomplished by extratropical cyclones ${ }^{22,23}$ and planetary-scale waves ${ }^{24}$. To further examine whether the moiststatic energy advection is affected by the individual decoupled mechanisms, we calculate the moist-static energy transport across $60^{\circ} \mathrm{N}$ for all experiments (see Methods). We find no considerable difference in either the mean state or the variability of moist-static energy transport between the experiments (Supplementary Fig. 8). We conclude that the pre-industrial monthly mean poleward moist-static energy transport is largely insensitive to the decoupled mechanisms. In line with previous studies ${ }^{19,23,25}$, these findings show that variations in advected moist-static energy primarily cause the tropospheric temperature fluctuations, which in turn predominantly drive sea-ice variability.

\section{Implications for interannual sea-ice predictability}

The dominating impact of advected atmospheric temperature fluctuations on sea ice has fundamental implications for the predictability of interannual sea-ice variability. The tight link between tropospheric temperature variability and sea-ice variability explains the lack of predictive skill for Arctic sea-ice area on yearly or longer timescales ${ }^{26}$. On these timescales, atmospheric temperature fluctuations are not predictable due to the nonlinear and chaotic nature of the climate system ${ }^{27}$. The control of sea-ice variability by atmospheric temperature might represent a predictability limit on Arctic sea-ice area $^{28}$.

The holistic quantifications of the dominant advected atmospheric temperature fluctuations-and the minor radiative feedbacks from surface albedo, clouds and water vapour, and the non-radiative forcings from surface winds and poleward oceanic temperature fluctuations-provide fundamental understanding of the origin of Arctic sea-ice variability. This understanding allows us to contextualize sea-ice fluctuations in the observed record and to interpret observed record lows in Arctic sea-ice area as a simple response to an unusually warm atmosphere.

\section{Online content}

Any methods, additional references, Nature Research reporting summaries, source data, statements of code and data availability and associated accession codes are available at https://doi.org/10.1038/ s41561-019-0363-1. 
Received: 19 December 2018; Accepted: 4 April 2019;

Published online: 13 May 2019

\section{References}

1. Fang, Z. \& Wallace, J. M. Arctic sea ice variability on a timescale of weeks and its relation to atmospheric forcing. J. Clim. 7, 1897-1914 (1994).

2. Ding, Q. et al. Influence of high-latitude atmospheric circulation changes on summertime Arctic sea ice. Nat. Clim. Change 7, 289-295 (2017).

3. Ukita, J. et al. Northern hemisphere sea ice variability: lag structure and its implications. Tellus A 59, 261-272 (2007).

4. Deser, C., Walsh, J. E. \& Timlin, M. S. Arctic sea ice variability in the context of recent atmospheric circulation trends. J. Clim. 13, 617-633 (2000).

5. Hall, A. The role of surface albedo feedback in climate. J. Clim. 17, 1550-1568 (2004).

6. Kashiwase, H., Ohshima, K. I., Nihashi, S. \& Eicken, H. Evidence for ice-ocean albedo feedback in the Arctic Ocean shifting to a seasonal ice zone. Sci. Rep. 7, 8170 (2017).

7. Letterly, A., Key, J. \& Liu, Y. The influence of winter cloud on summer sea ice in the arctic, 1983-2013. J. Geophys. Res. 121, 2178-2187 (2016).

8. Curry, J. A., Schramm, J. L., Serreze, M. C. \& Ebert, E. E. Water vapor feedback over the Arctic Ocean. J. Geophys. Res. 100, 14223-14229 (1995).

9. Lee, S., Gong, T., Feldstein, S. B., Screen, J. A. \& Simmonds, I. Revisiting the cause of the 1989-2009 arctic surface warming using the surface energy budget: downward infrared radiation dominates the surface fluxes. Geophys. Res. Lett. 44, 10654-10661 (2017).

10. Ogi, M., Yamazaki, K. \& Wallace, J. M. Influence of winter and summer surface wind anomalies on summer arctic sea ice extent. Geophys. Res. Lett. 37, L07701 (2016)

11. Årthun, M., Eldevik, T., Smedsrud, L. H., Skagseth, Ø. \& Ingvaldsen, R. B. Quantifying the influence of atlantic heat on barents sea ice variability and retreat. J. Clim. 25, 4736-4743 (2012).

12. Årthun, M. \& Eldevik, T. On anomalous ocean heat transport toward the arctic and associated climate predictability. J. Clim. 29, 689-704 (2016).

13. Zhang, R. Mechanisms for low-frequency variability of summer arctic sea ice extent. Proc. Natl Acad. Sci. USA 112, 4570-4575 (2015).

14. Miles, M. W. et al. A signal of persistent atlantic multidecadal variability in arctic sea ice. Geophys. Res. Lett. 41, 463-469 (2014).

15. Luo, D. et al. Winter eurasian cooling linked with the atlantic multidecadal oscillation. Environ. Res. Lett. 12, 125002 (2017).

16. Mauritsen, T. et al. Climate feedback efficiency and synergy. Clim. Dynam. 41, 2539-2554 (2013).

17. Luo, B., Luo, D., Wu, L., Zhong, L. \& Simmonds, I. Atmospheric circulation patterns which promote winter Arctic sea ice decline. Environ. Res. Lett. 12, 054017 (2017).

18. Pavelsky, T. M., Boé, J., Hall, A. \& Fetzer, E. J. Atmospheric inversion strength over polar oceans in winter regulated by sea ice. Clim. Dynam. 36, 945-955 (2011).

19. Graversen, R. G., Mauritsen, T., Drijfhout, S., Tjernström, M. \& Mårtensson, S. Warm winds from the Pacific caused extensive Arctic sea-ice melt in summer 2007. Clim. Dynam. 36, 2103-2112 (2011).

20. Screen, J. A., Deser, C. \& Simmonds, I. Local and remote controls on observed Arctic warming. Geophys. Res. Lett. 39, L10709 (2012).
21. Yang, X.-Y., Fyfe, J. C. \& Flato, G. M. The role of poleward energy transport in Arctic temperature evolution. Geophys. Res. Lett. 37, L14803 (2010).

22. Messori, G., Woods, C. \& Caballero, R. On the drivers of wintertime temperature extremes in the high arctic. J. Clim. 31, 1597-1618 (2018).

23. Wernli, H. \& Papritz, L. Role of polar anticyclones and mid-latitude cyclones for Arctic summertime sea-ice melting. Nat. Geosci. 11, 108-113 (2018).

24. Graversen, R. G. \& Burtu, M. Arctic amplification enhanced by latent energy transport of atmospheric planetary waves. Q. J. R. Meteorol. Soc. 142, 2046-2054 (2016).

25. Kapsch, M.-L., Skific, N., Graversen, R. G., Tjernström, M. \& Francis, J. A. Summers with low Arctic sea ice linked to persistence of spring atmospheric circulation patterns. Clim. Dynam. 52, 2497-2512 (2019).

26. Guemas, V. et al. A review on Arctic sea-ice predictability and prediction on seasonal to decadal time-scales. Q. J. R. Meteorol. Soc. 142, 546-561 (2016).

27. Kirtman, B. et al. Near-term Climate Change: Projections and Predictability in Climate Change 2013: The Physical Science Basis (eds Stocker, T. F. et al.) 953-1028 (IPCC, Cambridge Univ. Press, 2013).

28. Serreze, M. C. \& Stroeve, J. Arctic sea ice trends, variability and implications for seasonal ice forecasting. Phil. Trans. R. Soc. A 373, 20140159 (2015)

29. Fetterer, F., Knowles, K., Meier, W., Savoie, M. \& Windnagel, A. K. Sea Ice Index Version 3 (NSIDC, accessed 28 November 2017).

30. Dee, D. P. et al. The ERA-Interim reanalysis: configuration and performance of the data assimilation system. Q. J. R. Meteorol. Soc. 137, 553-597 (2011).

31. Balmaseda, M. A., Mogensen, K. \& Weaver, A. T. Evaluation of the ECMWF ocean reanalysis system ORAS4. Q. J. R. Meteorol. Soc. 139, 1132-1161 (2013).

\section{Acknowledgements}

We thank M.-L. Kapsch for helpful comments on an earlier version of this manuscript. This work was funded by the Max Planck Society. Extensive computational resources were made available by the German Climate Computing Centre. We thank PCMDI for their management of CMIP5, and the various modelling groups for carrying out the simulations used here.

\section{Author contributions}

D.O., T.M. and D.N. designed this study. D.O. and T.M. developed the methodology and D.O. conducted and analysed the experiments. All authors contributed to the interpretation of the results. D.O. wrote the manuscript with contributions and input from all authors.

\section{Competing interests}

The authors declare no competing interests.

\section{Additional information}

Supplementary information is available for this paper at https://doi.org/10.1038/ s41561-019-0363-1.

Reprints and permissions information is available at www.nature.com/reprints. Correspondence and requests for materials should be addressed to D.O.

Publisher's note: Springer Nature remains neutral with regard to jurisdictional claims in published maps and institutional affiliations.

(c) The Author(s), under exclusive licence to Springer Nature Limited 2019 


\section{Methods}

Decoupling methodology. The method of decoupling radiative feedbacks that we describe in detail here was initially developed for ECHAM6 ${ }^{16}$ and elaborated to study the role of clouds in El Niño ${ }^{32}$. Here, we implement the method into the fully coupled MPI-ESM1.2-LR to decouple the radiative feedbacks of clouds, water vapour and surface albedo in the atmosphere component ECHAM6.3 and the non-radiative forcing by surface winds and poleward oceanic heat transport in the ocean component MPIOM1.6. Rendering these potentially relevant mechanisms for sea-ice variability non-interactive in the otherwise fully coupled climate system allows us to quantitatively isolate their impacts on sea-ice variability.

The method consists of three steps. First, we perform a standard pre-industrial control simulation run for $250 \mathrm{yr}$ with fully interactive feedbacks and forcings, in which we read out all relevant instantaneous fields at every two-hourly radiation call. Second, we randomly select one of the fields from the 250 samples generated by the control simulation for the time of day and the day of the year. Third, the randomly selected field is read into the model's radiation calculations. The latter two steps are repeated every $2 \mathrm{~h}$ in 250 -yr-long simulations with an otherwise identical setup. This randomization renders the radiative feedbacks non-interactive because of the removal of spatiotemporal autocorrelation from one 2-h timestep to the next. For instance, we replace the model-simulated surface albedo with a random value from the pre-industrial control simulation such that the radiation code sees an uncorrelated surface albedo from a plausible model-simulated range from the same time of day and the same day of the year. In this experiment with a non-interactive surface-albedo feedback, we prescribe randomly sampled fields of ice and land surface albedo in the visible and near-infrared range. In the experiment with non-interactive cloud feedback, we prescribe the cloud liquid, cloud ice and cloud cover fraction on all levels used in the atmospheric radiation calculations. In the experiment with non-interactive water vapour feedback, we prescribe the three-dimensional specific humidity field used in the atmospheric radiation calculations. In all three experiments, the respective fields are randomly sampled timesteps of global fields from the pre-industrial control simulation.

We adapt the method to also prescribe the forcing by surface winds and poleward oceanic heat transport, with two differences. First, we output, randomly sample and input the relevant fields daily instead of every $2 \mathrm{~h}$. Second, we do not directly input the randomly sampled fields into the model calculations. To prescribe the surface-wind field globally, we input the randomly sampled fields of $10 \mathrm{~m}$ wind velocity and zonal and meridional wind stress on water and ice from the pre-industrial control simulation by flux adjustment. The flux adjustment adds artificial forcing terms to the wind fields such that the actual model-simulated fields are replaced by the randomly sampled fields from the pre-industrial control simulation. To randomize the poleward oceanic heat transport induced by densitydriven mixing, we nudge three-dimensional ocean temperature and salinity fields to the randomly sampled pre-industrial control-simulation values in a $5^{\circ}$ latitude band south of the winter sea-ice edge at $50-55^{\circ} \mathrm{N}$ in the Atlantic and $40-45^{\circ} \mathrm{N}$ in the Pacific at a relaxation time of $1 \times 10^{-5} \mathrm{~s}^{-1}$ such that the temperature and salinity fields are replaced within $1 \mathrm{~d}$. This randomization and nudging sustains the mean poleward oceanic heat transport in all experiments, but modifies its variability (Supplementary Fig. 9). The flux adjustment and nudging to randomly sampled fields from the pre-industrial control simulation thus decouple global surface winds and the oceanic heat transport towards the Arctic from the otherwise fully coupled climate system.

Collectively decoupling these previously suggested drivers of sea-ice variability narrows the remaining cause for sea-ice variability down to atmospheric temperature fluctuations. The atmospheric temperature fluctuations cannot be explicitly decoupled without running into an unstable climate. The Planck and lapse-rate feedbacks are not drivers for sea-ice variability, but depend on the atmospheric temperature.

Warming drift. The experiments in which we decouple the radiative feedbacks of clouds and water vapour show a warming drift in global-mean temperature. The warming drift arises because of prescribing the randomized order of the cloud and water vapour fields, which are powerful in altering the tight radiation balance. To compensate for this warming, which reduces the mean state of Arctic sea-ice area, we reduce the atmospheric $\mathrm{CO}_{2}$ concentration to $205 \mathrm{ppm}$ and $165 \mathrm{ppm}$, respectively (see Supplementary Table 1). We compensate the warming drift in the experiment in which all mechanisms are non-interactive by reducing the atmospheric $\mathrm{CO}_{2}$ concentration to $165 \mathrm{ppm}$. By doing so, the global-mean surface temperatures in all experiments deviates by less than $0.06^{\circ} \mathrm{C}$ from the value in the control simulation, and the mean state and seasonal cycle of Arctic sea-ice area are nearly identical in all experiments (Supplementary Table 1). This nearly identical mean state is crucial for this study, because the sea-ice variability is highly sensitive to the mean sea-ice state. We use the last $200 \mathrm{yr}$ of each experiment for all analyses, regarding this first $50 \mathrm{yr}$ as spin-up.

Limitations. Our method has two limitations. First, our quantification of the drivers of sea-ice variability is restricted to an unforced climate in pre-industrial climates. However, to test for a forcing dependence of the variability of the surface albedo, cloud, specific-humidity and surface-wind fields averaged over $60-90^{\circ} \mathrm{N}$, as well as the oceanic heat transport and the atmospheric energy transport at $60^{\circ} \mathrm{N}$, we determine the change in variability over time from MPI-GE (Maher, N. et al., manuscript in preparation). To do so, we calculate the ensemble standard deviation across the 100 ensemble simulations from annual averaged data for the historical and RCP8.5-forced period. The variability of the respective fields changes only slightly, indicating a similar relative role of the decoupled mechanisms and the atmospheric temperature fluctuations in a warming climate. Furthermore, the strong negative correlation of sea-ice variability with mid-tropospheric temperature fluctuations also holds for the observation period. Second, the method does not allow us to determine at which timescale the sea-ice variability originates, because the decoupling equally suppresses high- and low-frequency variability from $2 \mathrm{~h}$ to decadal timescales.

Observational data and reanalyses. We use the NSIDC passive microwave seaice concentration ${ }^{29}$ for sea-ice area, the ERA-Interim reanalysis ${ }^{30}$ for atmospheric temperature and the ORAS4 reanalysis ${ }^{31}$ for oceanic temperature. The quadratic fit is removed from all time series to account for the exponential evolution of both sea-ice area and atmospheric and oceanic temperatures. Similar correlations between sea-ice area and atmospheric and oceanic temperatures exist when detrending the temperature time series linearly (Atmosphere: $r=-0.52$, ocean: $r=-0.21$, see Fig. 1)

Significance testing. The significance of correlations is tested by applying a two-sided Student's $t$-test at the significance level $P=0.001$. Usage of different significant levels $(P=0.01$ or 0.1$)$ leads to qualitatively similar results. The correlation of NSIDC sea-ice concentration with ORAS4 temperature becomes significant at $P=0.2$; that is, a confidence level of $80 \%$ (see Fig. 1). The significance of differences in variances is tested by applying an f-test at the significance level $P=0.001$. Significantly different variances are stippled.

Correlation uncertainty between temperature and sea-ice area. The uncertainty of the correlation between atmosphere and ocean temperatures and sea-ice area is determined by subdividing the 200 -yr-long simulations into two 100 -yr-long chunks. The correlation is calculated for the two 100-yr-long chunks individually, and the respective range is shown as uncertainty bars in Fig. 4.

Energy transport calculation. To derive the poleward moist-static energy transport, we calculate the vertically integrated advection of dry-static and latent energy across $60^{\circ} \mathrm{N}$ as the sum of the contributions from transient eddies, the mean meridional circulation and stationary eddies ${ }^{33}$.

\section{Data availability}

Passive microwave sea-ice concentration data were obtained from http://nsidc. org/data/g02135; atmospheric temperature data from ERA-Interim and ocean temperature data from ORAS4 are available from http://www.ecmwf.int/en/ forecasts/datasets/browse-reanalysis-datasets/. CMIP5 model outputs were obtained from http://esgf-node.llnl.gov/ and ftp://ftp.ceda.ac.uk/.

\section{Code availability}

The MPI-ESM1.2-LR coupled climate model is distributed via http://www. mpimet.mpg.de/. The code changes to allow for non-interactive radiative feedbacks and non-radiative forcings (revision 8932) are available on request from publications@mpimet.mpg.de. All figures were generated using the NCAR Command Language $^{34}$, available at https://doi.org/10.5065/D6WD3XH5. Plotting scripts and relevant model output used in this study are available on request from publications@mpimet.mpg.de.

\section{References}

32. Rädel, G. et al. Amplification of El Niño by cloud longwave coupling to atmospheric circulation. Nat. Geosci. 9, 106-110 (2016).

33. Keith, D. W. Meridional energy transport: uncertainty in zonal means. Tellus A 47, 30-44 (1995).

34. NCAR Command Language v.6.3.0 (UCAR/NCAR/CISL/TDD, 2016) 